\title{
Post-Concussion Syndrome after a Mild Traumatic Brain Injury: A Minefield for Clinical Practice
}

\author{
Deborah L. Snell ${ }^{1,2 *}$, A. D. Sandy Macleod ${ }^{2}$, Tim Anderson ${ }^{3,4}$ \\ ${ }^{1}$ Department of Orthopaedic Surgery and Musculoskeletal Medicine, University of Otago, \\ Christchurch, New Zealand \\ ${ }^{2}$ Concussion Clinic, Brain Injury Rehabilitation Service, Burwood Hospital, Christchurch, New Zealand \\ ${ }^{3}$ New Zealand Brain Research Institute, Christchurch, New Zealand \\ ${ }^{4}$ Department of Medicine, University of Otago, Christchurch, New Zealand \\ Email: *debbie.snell@cdhb.health.nz
}

Received 4 February 2016; accepted 29 May 2016; published 1 June 2016

Copyright (C) 2016 by authors and Scientific Research Publishing Inc.

This work is licensed under the Creative Commons Attribution International License (CC BY). http://creativecommons.org/licenses/by/4.0/

(c) (i) Open Access

\begin{abstract}
In this clinical practice review, the controversies and difficulties managing post concussion symptoms following mild traumatic brain injury are discussed. Based on considerable clinical experience in a designated Concussion Clinic, the authors (a neuropsychologist, a psychiatrist, and a neurologist) review relevant literature and issues for clinical practice, particularly with respect to understanding risk factors for and vulnerability to, development of chronic post-concussion symptoms. We contend it is not just the kind of head that matters but also the kind of complications, the kind of outcomes and the kind of management that can influence injury recovery. Given these complexities, a bio-psychosocial conceptualization of chronic post-concussion syndrome is appropriate. Though understanding is still elusive, management should not be biased by physiogenic or psychogenic aetiological theories for management needs to address patient reported outcomes regardless of underpinning aetiology.
\end{abstract}

\section{Keywords}

Post-Concussion Syndrome, Mild Traumatic Brain Injury, MTBI, Chronic Injury Symptoms

\section{Introduction}

Post-concussion symptoms and the potentially enduring sequelae of mild traumatic brain injury (MTBI), such as

\footnotetext{
${ }^{*}$ Corresponding author.
}

How to cite this paper: Snell, D.L., Sandy Macleod, A.D. and Anderson, T. (2016) Post-Concussion Syndrome after a Mild Traumatic Brain Injury: A Minefield for Clinical Practice. Journal of Behavioral and Brain Science, 6, 227-232. 
chronic traumatic encephalopathy, are topical and controversial issues. Medical opinion has oscillated between those experts who consider organic factors crucial and those who believe in psychogenic aetiology, each viewpoint enjoying periodic fashionable times over the 150-odd years since these injuries has become more frequent because high velocity transport (the railway) has risked the health of the human brain. Contact sport and the blast injuries of modern warfare are the foci of present-day concerns. Symonds famously suggested in 1937 that after a MTBI, "the symptom picture depends not only on the kind of injury, but upon the kind of brain" ([1], p 1092). Lishman's seminal publication in 1988 proposed that organic factors were chiefly relevant in the early stages of the post-concussion syndrome (PCS), whereas long-continued symptoms were perpetuated by secondary neurotic developments [2]. The organic genesis and psychologically-driven persistence formulation were challenged by Jacobsen in 1995 who postulated that psychosocial and cognitive-behavioural factors and coping processes could influence post-concussion symptoms over their entire time course, in particular the late phase [3]. More recently Silverberg and Iverson (2011) agreed and suggested that neurobiological and psychological factors could play a causal role from the outset.

Psychiatrists' involvement in cases of MTBI generally concerns those who have not recovered and the constellation of symptoms (see Table 1) has become chronic and complicated by a host of psychosocial and medico legal issues. The patient's own reported outcome and perspective of the status of their recovery can be at times significantly at odds with the views of the clinician (and the insurer). Rarely, despite the hopes of the insurers, do sufferers of post-concussion symptoms conform neatly to diagnostic categories. We contend that adding to Symonds aphorism "the kind of complications", "the kind of management" and "the kind of outcome" may be appropriate.

The kind of complications Early post-concussion symptoms tends to have an organic signature but may rapidly acquire psychological embellishment and the eventual evolution of psychiatric symptoms. Symptoms morph from the physiological to the psychosomatic. Whereas acute PCS is best considered a neurological disorder (albeit a functional one); chronic PCS may be neuropsychiatric as over time there is increasing relevance of non-organic influences. In addition to typical symptoms of PCS (headache, fatigue, poor concentration, forgetfulness, noise and light sensitivity), a variety of psychological and physiological symptoms may complicate spontaneous recovery. The general public expects that symptoms will occur after a TBI [4] [5]. Indeed, attribution of symptoms to injury, expectations and understandings about symptom course and consequences, have been shown to be associated with, and predictive of outcome after MTBI [6] [7]. Paradoxically the increased public awareness of concussion suffered in sport and in combat may inadvertently increase the (mis)attribution of symptoms to a brain injury. Health anxiety and worry are probably key factors in the development of chronic PCS [8]. The losses of wellbeing, social role, employment, and recreation induce grieving and adjustment stressors. Over time dysphoria and dysthymia may emerge. Frank depression may evolve, especially in those with pre-existing affective risk factors [9]. Anger toward noxious litigation and insurance processes, even perhaps

\begin{tabular}{ccc} 
Table 1. Typical post-concussion symptoms. & & Emotional \\
\hline Symptom Domain: Somatic & Cognitive & Anxiety \\
Fatigue & Concentration problems & Irritability \\
Headache & Memory problems & Depression \\
Nausea & Slowed thinking & Personality changes \\
Vestibular and oculomotor symptoms & Word finding problems & \\
Visual disturbances & Reduced organization skills & \\
Light intolerance & & \\
Noise intolerance & \\
Sleep disturbance & \\
Balance problems & \\
Tinnitus & \\
Alcohol intolerance &
\end{tabular}


feelings of revenge toward the perpetrator of the injury (if there was one) may flavour affect, as may resentment toward yet another independent medical examination [10]. Traumatic brain injuries (TBIs) often occur in an "accident" setting and anger, fault, grief and distress may rapidly affect clinical status. Thus the symptoms of acute stress disorder (ASD) and acute post-traumatic stress disorder (PTSD) may be woven into the post-concussion symptoms. Disturbances of sleep are common after a brain injury. Hypersomnia, siestas and "naps" are often required in the acute phase and fragmentation of the nocturnal sleep pattern with prominent dreaming and parasomnia (as occurs in many neurological and neurodegenerative disorders) is common. Benign Postural and Position Vertigo is a very unpleasant complication (though usually responsive to treatment), likewise diplopia and anosmia. Central fatigue, the profound physical and mental exhaustion experienced in many traumatic, infective and oncological disorders of the brain, is debilitating and potentially demoralizing. This fatigue is enhanced with effort. Sustained concentration and short term memory may be compromised, this being particularly apparent in those who have cerebral occupations. The symptom constellation and complications resultant upon the head injury, and it is not possible to correlate type or location of trauma with potential clinical sequelae, significantly influences the induction of psychosocial complications. Seemingly trivial injuries may cause severe persisting PCS, particularly in those who have received previous TBIs and have a pre-injury compromised nervous system, or a pre-existing psychiatric disorder. As for severe TBIs the prognosis is difficult to predict and clinical surprises are not infrequent.

It is an appealing prospect in a disorder of uncertain pathogenesis, accompanied by psychological influences, and with medicolegal implications, to "blame" the sufferer and their pre-injury past for the condition. The most clinically challenging differential diagnosis involves establishing, or refuting, a causal connection between the residual symptoms and the injury. There may be a striking discrepancy between the reported "subjective" complaints of the patient and the presumably "objective" findings of the doctor leading inevitably to an uncomfortable state of cognitive dissonance in both parties and sometimes even open conflict [11] [12]. Certainly compensation possibilities may encourage "sick role" ideations. Determining malingering, exaggeration, symptom magnification and poor effort may be a clinical task addressed to psychiatry. Malingering is probably rare, though the base rates have been reported to be high [13]. Though not all studies indicate a negative effect of litigation [14], some individuals surely find the opportunity too attractive, despite the dishonesty involved. Binder in a meta-analysis suggested financial incentives may account for $20 \%-30 \%$ of abnormal signs and symptoms, with those who are symptomatic more likely to be seeking compensation [15]. Malingering is not the primary, or indeed only, cause of below-capacity performance [10]. Symptom exaggeration is though common. Some form of illness behaviour is probably a universal response and differentiating normal and abnormal illness behaviours is an imprecise clinical opinion. Clinical signs such as patchy sensory loss, non-pronator drift, or normal backward but not forward gait, probably don't differentiate from conversion disorder. Neuropsychological "effort testing" has become an established practice by the insurance industry yet it is fraught with scientific doubt, bias and misinterpretations. Many of these tests are "forced-choice" and cut-off levels are not uniform, the context of performing the testing may be confrontational and situational stress and anxiety, are relevant confounders. Choking under pressure and trying too hard can affect performances on cognitive tests [10]. Stereotype threat, the observation that society's bias of a subgroup affects performance, has not been scientifically evaluated and the influences of "ego-depletion", the capacity to exert self-control, impulsivity and fatigue may contaminate performance. Differentiating conscious, intentional poor effort from pathological impaired performance is difficult. "Cheating" usually of a minor nature is a common human "normal" behaviour, money may affect both patient and independent expert and involvement in litigation may adversely affect prognosis. However emerging inconsistent findings and difficulties replicating results regarding the influences of compensation from earlier studies, especially in jurisdictions outside the US, are contributing to more thoughtful discussions [10] [16]. The forensic implications of chronic post concussion symptoms further enhance the complexity of the syndrome and distract from treatment.

\section{The Kind of Management}

The vast majority of concussive cases do not require any specific treatment and recover, typically within 3 months or so, with no lasting clinical sequelae. There are few evidence-based clinical management guidelines for those whose symptoms persist [17] beyond those focusing on sports concussion management. Recent published guidelines for managing persisting MTBI symptoms by the Ontario Neurotrauma group may be helpful 
[18]. The appropriateness and adequacy of acute management may, however, be a critical influence determining the persistence of symptoms. After the need for neurosurgical and otological interventions has been discounted, early and confident reassurance and encouragement that the condition is transient and full recovery is expected is advisable. Indeed these are the only approaches currently supported by the evidence (Nygren-de Boussard 2014: Snell 2009). The provision of information about MTBI, strategies to prevent further injury, advising selfmonitoring of symptoms (using the symptoms as a "temperature gauge" and pacing activities within symptominduced limitations), the avoidance of alcohol and cannabis (the "silent saboteurs" of brain injury recovery [3]), sleep hygiene, graded aerobic exercises, and initial activity restriction before a gradual resumption of pre-injury activities (work/school/leisure) are helpful early clinical options [17] [19]. Symptomatic relief of headache and neck pain with minor analgesics is generally provided, though continuing regular use risks chronic daily headache. Traditionally an initial, though brief physical and cognitive rest period, to take the "work load" off the brain, has been universally recommended. Cognitive rest refers to the minimization or avoidance of scholastic work, videogames, computing and text messaging during the rest period [20]. However within several days strict physical rest deconditions cardiopulmonary and musculoskeletal systems. There is expert consensus, but not supportive trials, that complete rest exceeding three days is not helpful, and that gradual resumption of pre-injury activities should begin as soon as tolerated [21]. Most are inclined to 'push' limits, the concerning minority placing themselves in 'cotton wool'. Patients consistently underestimate their premorbid experiences of headache, fatigue, inattention, memory difficulties, dysphoria, visual acuity [4] [22]. More formal cognitive restructuring-reattributing of subjective symptoms to normal causes may be indicated for those unimpressed by the expert's reassurances. Neurocognitive rehabilitation, used widely in severe TBI, is of inconclusive benefit for MTBI [19] [20]. Iatrogenic amplification of symptoms can occur. Giving discouraging prognosis, excessive testing and assessment, and unnecessary treatment will increase anxiety and illness-related behaviours [23]. Neuro-imaging, if not indicated on clinical grounds, rarely relieves convictions of organic damage. Neuropsychological examination can be therapeutic in disconfirming cognitive impairment. Many, without guidance, are likely to return to work too early and a failed return to work undermines subsequent return to work confidence [24]. The skilful clinical titration of informed reassurance and supporting a graded resumption of pre-injury activities is the key to managing recovery and aborting the health anxiety induced by the injury. The major focus of management is to prevent discouragement, check any emergent abnormal illness behaviours, and orchestrate a graded and gradual return to full function (and employment). Despite the above ideal management some experience persistence of symptoms.

\section{The Kind of Outcome}

Post-concussion symptoms appear to be self-limiting for most and follow a predictable course of spontaneous recovery over days to weeks. A waxing and waning of symptoms, usually in response to situational stressors, such as over-exertion when feeling better and mental health influences is however usual. When followed up at three, six and 12 months respectively, approximately a half, a quarter and an eighth of MTBI patients have significant post-concussion symptoms [8]. In our own incept cohort study, 50.3\% of the sample of 147 cases met criteria for a poor outcome (PCS) at an average of six weeks after a MTBI, with this falling to $24.8 \%$ at an average of 7 months post injury [6] [25]. Persisting symptoms are associated with high levels of disability and health care service utilization [26]. Some continue to report symptoms and reduced quality of life long after they have freed themselves from the often distressing process of seeking compensation and even after they may have returned to employment. Most insurers (and some clinicians) would consider a return to work a "good" outcome. Nevertheless, these individuals may also continue to report symptoms such as headaches and fatigue and identify negative psychosocial impacts of these persisting symptoms such as feeling disconnected from their pre-injury world [27] [28], relationship breakdown, threats to loss of status and career opportunities, and fiscal impacts [16] [26] [29] [30]. The diagnostic criteria for PCS for those who experience persisting symptoms more than one to three months, are controversial. Much of the MTBI literature concerns athletes who are usually young, fit and motivated to recover, and in whom the mechanism of injury is different to that of a motor vehicle accident or a blast injury [20]. Determining outcome can be particularly challenging in those with pre-injury neurological and psychological vulnerability. The symptoms of PCS are non-specific, and indeed healthy persons with no history of head trauma confess to experiencing these symptoms in daily life [31].

Polarized positions are unhelpful and do not advance the field, rather frameworks capable of coping with 
multifactor influences such as bio-psychosocial models are likely to be more constructive. The bio-psychosocial genesis of the syndrome is multi-determined, individualistic and muddy, yet this is the only appropriate conceptualization of this disorder (see [17] for a good discussion). In view of the non-specificity of the PCS, and indeed the diagnostic doubts associated with this syndrome, it is perhaps preferable to consider post-concussion symptoms rather than the syndrome [14]. For the clinician, understanding PCS remains elusive yet this should not affect management which is the same regardless of physiogenesis or psychogenesis [8]. Organic dysfunction of the nervous system, particularly if consciousness is interfered with, is likely to compromise the mind and its functioning. Cartesian models are inadequate to account for PCS and such dichotomies can be unhelpful and misleading [16]. Perhaps in the MTBI literature, the nosological and classification issues and debates about veracity of the patient's account have been too distracting. The continuing advancement of an evidence base for underpinning factors when symptoms persist will help to address the challenging discrepancies between subjective experiences of the patient and objective findings of the clinician. As chronicity comes the need to introduce a multidisciplinary and multifocal approach, each expert addresses and treats the various components of the syndrome. With an evidence base guiding targeted early intervention, the hope is that the uneasy task for the psychiatrist and psychologist of deciphering and managing post-concussion symptoms that have long become chronic will be less fraught, if not less complicated. Finally, the patient's perspective of their health is integral to understanding health outcomes. More attention to and respect for patient reported outcomes is needed if we truly wish to improve the health and quality of life for those who suffer persisting consequences of a MTBI.

\section{References}

[1] Symonds, C. (1937) Mental Disorder Following Head Injury. Proceedings of the Royal Society of Medicine, 3, 10811092.

[2] Lishman, W. (1988) Physiogenesis and Psychogenesis in the Post Concessional Syndrome. British Journal of Psychiatry, 153, 460-469. http://dx.doi.org/10.1192/bjp.153.4.460

[3] Jacobson, R. (1995) The Post-Concussional Syndrome: Physiogenesis, Psychogenesis and Malingering. An Integrative Approach. Journal of Psychosomatic Research, 39, 675-693.

[4] Mittenberg, W., DiGiulio, D., Perrin, S. and Bass, A. (1992) Symptoms Following Head Injury: Expectation as Etiology. Journal of Neurology, Neurosurgery and Psychiatry, 41, 611-616. http://dx.doi.org/10.1136/jnnp.55.3.200

[5] MacKenzie, J. and McMillan, T. (2005) Knowledge of Post-Concussional Syndrome in Naive Lay-People, General Practitioners and People with Minor Traumatic Brain Injury. The British Journal of Clinical Psychology, 44, 417-424. http://dx.doi.org/10.1348/014466505X35696

[6] Snell, D., Hay-Smith, E., Surgenor, L. and Siegert, R. (2013) Predicting Long-Term Outcome after Mild Traumatic Brain Injury: The Contribution of Injury Beliefs and Leventhal's Common Sense Model. Neuropsychological Rehabilitation, 23, 333-362. http://dx.doi.org/10.1080/09658211.2012.758419

[7] Whittaker, R., Kemp, S. and House, A. (2007) Illness Perceptions in Mild Head Injury. Journal of Neurology, Neurosurgery, and Psychiatry, 78, 644-646. http://dx.doi.org/10.1136/jnnp.2006.101105

[8] Fleminger, S. (2011) Is Post Concessional Syndrome due to Brain Damage. Advances in Clinical Neuroscience and Rehabilitation (ACNR), 10, 9-10.

[9] Carroll, L., Cassidy, J., Cancelliere, C., Côté, P., Hincapié, C., Kristman, V., et al. (2014) Systematic Review of the Prognosis after Mild Traumatic Brain Injury in Adults: Cognitive, Psychiatric, and Mortality Outcomes: Results of the International Collaboration on Mild Traumatic Brain Injury Prognosis. Archives of Physical Medicine and Rehabilitation, 95, S152-S173. http://dx.doi.org/10.1016/j.apmr.2013.08.300

[10] Silver, J. (2012) Effort, Exaggeration and Malingering after Concussion. Journal of Neurology, Neurosurgery and Psychiatry, 83, 836-841. http://dx.doi.org/10.1136/jnnp-2011-302078

[11] Benton, A. (1989) Historical Notes on the Post-Concussion Syndrome. In: Levin, H., Eisenberg, H. and Benton, A., Eds., Mild Head Injury, Oxford University Press, New York.

[12] Prigatano, G. and Gale, S. (2011) The Current Status of Post-Concussion Syndrome. Current Opinion in Psychiatry, 24, 243-250. http://dx.doi.org/10.1097/YCO.0b013e328344698b

[13] Mittenberg, W., Patton, C., Cayock, E. and Condit, D. (2002) Base Rates of Malingering and Symptom Exaggeration. Journal of Clinical and Experimental Neuropsychology, 24, 1094-1102.

[14] McAllister, T. (2005) Mild Brain Injury and the Post-Concussional Syndrome. In: Silver, J., McAllister, T. and Yudofsky, S., Eds., Textbook of Traumatic Brain Injury, American Psychiatric Publishing, Arlington.

[15] Binder, L. (1993) Assessment of Malingering after Mild Brain Trauma with the Portland Digit Recognition Test. 
Journal of Clinical and Experimental Neuropsychology, 15, 170-182. http://dx.doi.org/10.1080/01688639308402555

[16] Ruff, R. (2011) Mild Traumatic Brain Injury and Neural Recovery: Rethinking the Debate. NeuroRehabilitation, 28, $167-180$.

[17] Iverson, G., Silverberg, N., Lange, R. and Zasler, N. (2012) Conceptualizing Outcome from Mild Traumatic Brain Injury. In: Zasler, N., Katz, D. and Zafonte, R., Eds., Brain Injury Medicine: Principles and Practice, 2nd Edition, Demos Medical Publishing, New York, 470-497.

[18] Marshall, S., Bayley, M., McCullagh, S., Velikonja, D., Berrigan, L., Ouchterlony, D., et al. (2015) Updated Clinical Practice Guidelines for Concussion/Mild Traumatic Brain Injury and Persistent Symptoms. Brain Injury, 29, 688-700. http://dx.doi.org/10.3109/02699052.2015.1004755

[19] Snell, D., Surgenor, L., Hay-Smith, E. and Siegert, R. (2009) A Systematic Review of Psychological Treatments for Mild Traumatic Brain Injury: An Update on the Evidence. Journal of Clinical \& Experimental Neuropsychology, 31, 20-38. http://dx.doi.org/10.1080/13803390801978849

[20] Khurana, V. and Kaye, A. (2012) An Overview of Concussion in Sport. Journal of Clinical Neuroscience, 19, 1-11. http://dx.doi.org/10.1016/j.jocn.2011.08.002

[21] Silverberg, N. and Iverson, G. (2013) Is Rest after Concussion “The Best Medicine"? Recommendations for Activity Resumption Following Concussion in Athletes, Civilians, and Military Service Members. Journal of Head Trauma Rehabilitation, 28, 250-259. http://dx.doi.org/10.1097/HTR.0b013e31825ad658

[22] Iverson, G., Lange, R., Brooks, B. and Ashton Rennison, V. (2010) “Good Old Days” Bias Following Mild Traumatic Brain Injury. The Clinical Neuropsychologist, 24, 17-37. http://dx.doi.org/10.1080/13854040903190797

[23] Rees, P. (2003) Contemporary Issues in Mild Traumatic Brain Injury. Archives of Physical Medicine \& Rehabilitation, 84, 1885-1894. http://dx.doi.org/10.1016/j.apmr.2003.03.001

[24] Mateer, C. (1992) Systems of Care for Post-Concussive Syndrome. In: Horn, I. and Zasler, N., Eds., Rehabilitation of Post-Concussive Disorders, Henley \& Belfus, Philadelphia, 143-155.

[25] Snell, D., Surgenor, L., Hay-Smith, E., Williman, J. and Siegert, R. (2015) The Contribution of Psychological Factors to Recovery after Mild Traumatic Brain Injury: Is Cluster Analysis a Useful Approach? Brain Injury, 29, $291-299$. http://dx.doi.org/10.3109/02699052.2014.976594

[26] King, N. and Kirwilliam, S. (2011) Permanent Post-Concussion Symptoms after Mild Head Injury. Brain Injury, 25, 462-470. http://dx.doi.org/10.3109/02699052.2011.558042

[27] Levack, W., Kayes, N. and Fadyl, J. (2010) Experience of Recovery and Outcome Following Traumatic Brain Injury: A Metasynthesis of Qualitative Research. Disability and Rehabilitation, 32, 986-999. http://dx.doi.org/10.3109/09638281003775394

[28] Barker-Collo, S., Jones, K., Theadom, A., Starkey, N., Dowell, A., McPherson, K., et al. (2015) Neuropsychological Outcome and Its Correlates in the First Year after Adult Mild Traumatic Brain Injury: A Population Based New Zealand Study. Brain Injury, 29, 1604-1616. http://dx.doi.org/10.3109/02699052.2015.1075143

[29] Gilworth, G., Eyres, S., Carey, A., Bhakta, B. and Tennant, A. (2008) Working With a Brain Injury: Personal Experiences of Returning to Work Following a Mild or Moderate Brain Injury. Journal of Rehabilitation Medicine, 40, $334-$ 339. http://dx.doi.org/10.2340/16501977-0169

[30] Wood, R.L. (2004) Understanding the "Miserable Minority": A Diathesis-Stress Paradigm for Post-Concussional Syndrome. Brain Injury, 18, 1135-1153. http://dx.doi.org/10.1080/02699050410001675906

[31] Iverson, G. and Lange, R. (2003) Examination of "Postconcussion-Like" Symptoms in a Healthy Sample. Applied Neuropsychology, 10, 137-144. http://dx.doi.org/10.1207/S15324826AN1003 02

\section{List of Abbreviations}

MTBI Mild traumatic brain injury

PCS Post concussion syndrome

TBI Traumatic brain injury

ASD Acute stress disorder

PTSD Post traumatic stress disorder 